\title{
Experiências autoformadoras de Licenciados em Educação Física no PIBID: aprendizagens de si para Docência
}

\author{
Self-training experiences of graduates in Physical Education of the \\ Institutional Program of Scholarship for Teaching Initiation: self-learning for \\ teaching
}

Samara Moura Barreto de Abreu ${ }^{*}$, Andreyson Calixto de Brito ${ }^{1}$, Basílio Rommel Almeida Fechine $^{1}$

ARTIGO ORIGINAL | ORIGINAL ARTICLE

\begin{abstract}
Este trabalho evidencia as experiências autoformadoras do PIBID com as narrativas de licenciados do curso de Educação Física do Instituto Federal de Educação, Ciência e Tecnologia do Ceará - campus Canindé. Objetiva-se compreender a autoformação de licenciados em Educação Física do Programa enquanto aprendizagem para a docência. Esta investigação descritiva de abordagem qualitativa adotou o método autobiográfico, tomando como corpus de análise o contexto das narrativas de si e apresenta análises interpretativas fundamentadas nas formulações de autores como Pineau (1988), Ferrarroti (2014), Mizukami (2010) e Josso (2004, 2007). As análises, a partir das experiências em foco, evidenciam que o Programa Institucional de Bolsas de Iniciação à Docência desenvolveu experiências autoformadoras, uma vez que produziu aprendizagens docentes existenciais, instrumentais e relacionais como representações das marcas do vivido.

Palavras-chave: educação física, aprendizagem docente, Programa Institucional de Bolsas de Iniciação à Docência, narrativas de si.
\end{abstract}

ABSTRACT

This work evidences the self-training experiences of the PIBID with the autobiographical narratives of graduates in Physical Education of the Federal Institute of Education, Science and Technology of Ceará Canindé campus. It aims to understand the self-training of graduates in Physical Education of the Program as learning for teaching. This descriptive research adopted the qualitative approach and the autobiographical method, taking as corpus of analysis the context of the autobiographical narratives and presents interpretative analyzes based on the formulations of authors as Pineau (1988), Ferrarroti (2014), Mizukami (2010) and Josso $(2004,2007)$. The analyzes, based on the focused experiences, show that the Institutional Program of Scholarship for Teaching Initiation developed self-training experiences because it produced existential, instrumental and relational teaching learning as representations of lived experience. Keywords: physical education, teaching learning, institutional program of scholarship for teaching initiation, autobiographical narratives.

\footnotetext{
${ }^{1}$ Instituto Federal de Educação, Ciência e Tecnologia do Ceará - IFCE, Canindé, Brasil

* Autor correspondente: samara.abreu@ifce.edu.br
} 


\section{INTRODUÇÃO}

A formação de professores nesses tempos estarrecedores de crise política-educacional vem reclamar por uma mudança educativa (Garcia, 1999) implicada na autonomia e empoderamento dos processos de profissionalidade e desenvolvimento profissional docente que dialoguem sobre os modos de produzir a vida, produzir a profissão e produzir a escola (Nóvoa, 1992) em dimensão (auto)formadora (Pineau, 1988), tomada como construto dialético de relações intersubjetivas, na interação tríade, entre o 'eu', o 'outro' e o “meio" (Pineau, 1988 \& Galvani, 2002).

Neste sentido, torna-se emergente incorporar nos programas de formação de professores experiências concernentes a aquisição de conhecimentos, competências e atitudes que permitam aos professores em formação compreender as complexas situações de ensino" (Garcia, 1999). Além disso, que superem uma racionalidade técnica com vistas a uma racionalidade pedagógica (Therrien, 2006), sobretudo, sobre as clivagens históricas na Educação Física (Bracht, 1999).

O Programa Institucional de Bolsas de Iniciação a Docência(PIBID) foi lançado em 2007 pelo Ministério da Educação MEC/Capes (Brasil, 2007), destinado inicialmente para licenciaturas de Matemática, Física, Química, Biologia e Matemática pela carência de profissionais no magistério nessa área. Apenas em 2009, teve uma ampliação para atender as demais licenciaturas, incluindo a Educação Física (Pinto, 2014). Vem se colocando como uma ação afirmativa fecunda no campo da formação de professores em construto de uma rede colaborativa entre universidade-escola (Farias \& Rocha, 2002; Pinto, 2014; Medeiros et al, 2017), ao mesmo tempo em que sofre ataques econômicos frente às politicas neoliberais (Medeiros et al, 2017).

O Pibid traz como imperativo a preocupação com a aprendizagem docente, compreendida em movimento de reflexividade na ação e sobre a ação (Schon, 1992) educativa. Conforme orienta Mizukami (2010), a aprendizagem docente deve ser mediatizada nas implicações na e sobre problemas da prática em competência reflexiva, tomada por conhecimentos e atitudes.

Implicados reflexivamente sobre a formação e aprendizagem docente em Educação Física pelo Pibid, no contexto de pertencimento deste programa num Curso de Licenciatura em Educação Física campus Canindé, no interior do Ceará, questionamos: Como o PIBID (auto)forma professores de Educação Física? Que aprendizagens para a docência são constituídas nesse programa? Assim, o objetivo do estudo foi compreender a autoformação de licenciados em Educação Física no Pibid como aprendizagem para a docência. A justificação como dimensão epistemológica se constitui pela lacuna de estudos pautados sobre a Educação Física e PIBID conforme estudos realizados por Pinto(2014) e Medeiros et al (2017), e como dimensão sociocrítica, a ideação de mudança educativa encarnada sobre nós 'agentes e autores' (Ardoino, 1998) pedagógicos, em busca transformadora.

\section{MÉTODO}

Realizamos um estudo empírico, de natureza qualitativa, delineado para o método autobiográfico. Para Ferrarotti (2014), o metódo autobiográfico conduz o pesquisador a reconhecer os saberes junto com o outro em conversação, em narrativas.

A utilização do método autobiográfico se coloca como escolha teórico-metodológica no campo da formação docente pela possibilidade de um duplo movimento - a investigação sobre o processo de formação e a compreensão subjetiva de sentimentos e representações dos atores sociais de sua autoformação pela narrativa de si (Souza, 2006), aqui definida pela experiência formativa no Pibid.

\section{Participantes}

Constituímos como lócus investigativo a experiência de formação no PIBID no Curso de Licenciatura de Educação Física do Instituto Federal de Educação, Ciência e Tecnologia do Ceará, campus Canindé, no interior do estado. Os sujeitos-autores da pesquisa foram os licenciados egressos deste curso que participaram do subprojeto do PIBID Educação Física, durante a 
vigência desse programa (2011-2014). Como critérios de inclusão da amostra definimos: 1atuação vigente no magistério na Educação Física Escolar, 2- participação no subprojeto do PIBID Educação Física pelo período mínimo de 6 meses. Com base nesses critérios, participaram 11 sujeitos, sendo 4 do sexo masculino e 7 do sexo feminino, com média de idade de 26,18 anos.

\section{Instrumentos e Procedimentos}

A coleta de dados foi feita a partir da análise documental dos memoriais de formação desenvolvidas como atividade pedagógica proposta do Curso de Especialização em Educação Física Escolar, no ínterim da disciplina de Didática em Educação Física ofertada no semestre 2017.1, em que os licenciados apresentam sua história de vida e formação. Conforme nos diz Passegi (2002, p.74) "as histórias de vida, nesse sentido, permitem a observação de como as experiências de transformação vão sendo geradas e compreendidas, e se revelam como um material "perfeito" para apreender os segredos da historicidade do sujeito". O teor do corpus de análise sobre os memoriais para esse objeto de investigação foi trazido à luz da tematização sobre o Pibid. Como procedimentos éticos estivemos implicados na resolução 510/16 do CNS.

\section{Análise estatística}

A representação do corpus de análise intepretativa foi tomada pelas narrativas de si, produzidas nos memoriais de formação dos licenciados. Após apreensão do corpus em tematização sobre o PIBID, utilizamos a análise interpretativa compreensiva (Ricouer, 1996) a partir da experiência da narrativa de si (Souza, 2006). Adotamos como elemento de triangulação desse entendimento e análise a relação entre o objeto de estudo, seus objetivos e a perspectiva hermenêutica, pela análise documental das narrativas autobiográficas.

\section{RESULTADOS E DISCUSSÃO}

Serão identificados os referenciais que servem para pensar e dar sentido às aprendizagens sobre a docência em Educação Física pela experiência no Pibid a partir do vivido. Buscamos, a partir das contribuições de Josso (2007), evidenciar as aprendizagens docentes, caracterizando-as em: existenciais (ser no mundo), aprendizagens instrumentais (processos e procedimentos) e aprendizagens relacionais (troca/comunicação com o outro) expressos em maior convergência pelos licenciados.

Sobre as aprendizagens existenciais, foi destacado pelos sujeitos-autores (7), a dimensão da inteligibilidade do sensível, pela escuta do outro, do cuidado, da experiência dialogal como conhecimento do outro e em direção do conhecimento de si na docência. Destacamos alguns excertos:

Meu desafio foi com o PIBID, no qual fiquei durante quase 3 anos, vivenciando as melhores experiências no campo docente. Foi o divisor de águas para chegar onde estou atualmente, para me descobrir nessa área e para encarar o ser docente, onde descobri que você não é apenas um professor; mas um amigo, um confidente, um conselheiro (sujeito-autora 1).

No final do segundo semestre consegui uma tão sonhada bolsa, comecei a participar do PIBID. Foi uma experiência nova pra mim, confesso que tive muito meio e receio pois era minha iniciação a docência e aquilo me causava medo, ter contato com os alunos de uma escolas, jovens adolescentes como eu, me senti tímida diante desse desafio, mas enfrentei meus medos e comecei a trabalhar, com o tempo foi se tornando algo bom, o medo foi embora e eu abracei com uma experiência para o futuro. Aprendi muitas coisas, a partir dali já pensava em atuar como professora, já via admiração, mas era algo que ainda precisava ser trabalhado dentro de mim, por que quando pensava em tal eu senti medo, ficava me imaginado, será que seria capaz (sujeito-autora 5).

Em palavras é complicado descrever o valor do Projeto PIBID em minha vida, um projeto que me proporcionou conhecer a realidade da educação física nas escolas e a partir dos aprendizados nesta jornada construirmos o nosso profissional. Sempre estudei em escola pública e minha vivência em aulas de educação física, foram poucas as vivencias 
pois quase sempre eram ministradas da mesma forma, e quando entrei na graduação e ao conhecer o projeto PIBID pude entender se era isso mesmo que queria para a minha vida (sujeito-autora 7 ).

Conforme estas narrativas de si, identificamos o PIBID como um momento-charneira (Josso, 2004), um 'divisor de águas', referenciado pelo desbravar dos períodos significativos do percurso de vida de cada um (Josso, 2004), as (re)ações sobre o choque da realidade na iniciação à docência, com necessária busca do autoconhecimento e apreensão dialogal.

Ainda como representação da aprendizagem existencial, foi demarcado (2 sujeitos) as representações dos dilemas e as condições de resiliência para continuidade no programa e na formação acadêmica, sobremaneira, para a (in) sustentabilidade financeira:

No PIBID comecei a lecionar em Itatira a mais de $100 \mathrm{~km}$ de Canindé, me deslocava na minha moto e sem ajuda de custo, outra bolsista que também trabalhava neste município rachava as despesas comigo, era uma viagem perigosa e cansativa, saíamos ao meio dia, logo após o termino da aula, comíamos um lanche rápido e partíamos em pleno o Sol do meio dia pra nossa jornada de educadores [...] essas experiências foram primordiais para minha formação como professor, o referido programa foi de grande relevância para que eu ao sair da graduação tivesse um perfil de professor de qualidade e de destaque (sujeito-autor 2).

Mais foi no Programa Institucional de Bolsa de Iniciação a Docência (PIBID) onde, veio a minha definição como professor e tive o prazer de ganhar a bolsa e participar desse programa de 2014 a 2016 em duas escolas, onde ganhávamos uma quantia em dinheiro para ajudar na nossa formação (sujeitoautor 9).

Segundo Josso (2004, p.43), "a narrativa de um percurso intelectual e de práticas de conhecimento põe em evidência os registros da expressão dos desafios de conhecimento ao longo de uma vida. Esses registros são conhecimentos elaborados em função de sensibilidades particulares em um dado período".

No que tange as aprendizagens instrumentais (processos e procedimentos), os licenciados(11) evidenciaram o construto de experiências didática-pedagógicas na realidade de planejamento, sistematização, o desenvolvimento de oficinas, a organização de eventos da área específica cujos destaques:

Esse programa foi despertando mais fortemente em mim a carreira docente, os planos de aula, o contato mais forte com a escola, com os alunos, as oficinas desenvolvidas. As oficinas eram mais diversificadas possível, queríamos mostrar os diferentes conteúdos e atividades que permeava a Educação Física para os alunos. E mesmo sendo oficina de modalidades esportivas tínhamos que contextualizar de uma forma diferente, na qual abordava a temática como, por exemplo, futsal para além da quadra, outras como lutas na escola: luta não é violência, expressão corporal, dança, jogos populares, capoeira, ginástica, hidroginástica, natação, vôlei etc. (sujeitoautora 4).

Minha vida profissional começou ainda durante minha graduação, quando comecei a dar aulas em um programa (Programa Institucional de Bolsa de Iniciação à Docência - PIBID) no ano de 2011 em uma cidade vizinha (Itatira), na E. E. F. M. Antonio Sabino Guerra, lá atuei por 1 ano em aulas de atletismo; jogos populares, prédesportivos e cooperativos; auxiliei um professor em aulas de futsal; no ano de 2012 ainda participando do mesmo programa comecei a ter o primeiro contato com a E. E. F. M. Frei Policarpo, dando aulas de futsal e posteriormente de natação (sujeito-autora $3)$.

No Pibid, nós licenciandos éramos inseridos no cotidiano de escolas da rede pública de educação, as quais tínhamos oportunidades de criação e participação em experiências metodológicas, tecnológicas e práticas docentes de caráter inovador e interdisciplinar que buscasse a superação de problemas identificados no processo de ensino-aprendizagem. E ainda tínhamos a 
oportunidade de participar nas atividades de planejamento do projeto pedagógico da escola, bem como participação nas reuniões pedagógicas (sujeito-autora 8).

Verificamos, portanto, aprendizagens sobre o conhecimento pedagógico e o conhecimento específico em atravessamento de uma cultura técnica para uma cultura crítica da Educação Física, posta em realidade da diversidade de conteúdos, e em descontinuidade da cultura esportivista.

Também é possivel percebermos a dimensão da intersubjetividade elucidada pelos licenciados (8) como aprendizagem relacional, aludidada pela relação e troca de saberes com a supervisora e entre bolsistas, reiterada em algumas narrativas:

[...]Tive uma experiência mais real da docência proporcionada por minha supervisora que me convidava a participar da semana pedagógica desta, dos planejamentos junto com outros professores, ajudar no interclasse (sujeitoautora 3).

A relação de interação e troca de saberes com os outros bolsistas e duplas, as formações, relatórios, frequências e demais contextos que requer nosso compromisso e responsabilidade (sujeito-autora 4).

Conforme analítica hermenêutica, presenciamos a dialogicidade e a compreensão pedagógica dos aspectos disciplinares, técnicos e sociais num movimento de auto-organização, que implica a uma maior reflexividade crítica, pela heteroformação e ecoformação (Macedo, 2010 \& Pineau, 1988), ou seja, de ações cognitivas e de pensamentos reflexivos formativos a respeito de processos de (auto)formação.

\section{CONCLUSÕES}

Pelas narrativas de si dos licenciados na experiência do PIBID foram descortinados resultados que nos possibilitam perceber a presença de elementos formativos que expressam relações de alteridade, sensibilidade e resiliência nas representações das marcas do vivido, matizados por elementos da vida e formação no PIBID, como aprendizagens existenciais, instrumentais e relacionais, evidenciando experiências autoformadoras para a docência

Evocamos o necessário investimento em estudos sobre o PIBID como afirmação de um programa de formação docente pautada na perspectiva de uma educação emancipatória, crítica, de autonomia e autorização docente, sobretudo, no campo da educação física, em ressignificação das clivagens históricas tradicionais de uma racionalidade eminentemente técnica.

\begin{abstract}
Agradecimentos:
Ao Instituto Federal de Educação, Ciência e Tecnologia do Ceará (IFCE); Programa de Pós-Graduação em Educação (PPGE/ UECE) e ao Programa Insitucional de Bolsas de Iniciação à Docência (PIBID/IFCE). Aos Grupos de Pesquisa: Educação, Saúde e Exercício Físico (IFCE); Grupo Educação, História e Saúde Coletiva (UECE); Grupo de Estudos e Pesquisa em Educação Física Escolar (UECE).
\end{abstract}

\section{Conflito de Interesses:}

Nada a declarar.

\section{Financiamento:}

Coordenação de Aperfeiçoamento de Pessoal de Nível Superior (CAPES/PIBID), Centro de Desenvolvimento do Esporte Recreativo e do Lazer (REDE CEDES Ceará).

\section{REFERÊNCIAS}

Ardoino, J. (1998). Abordagem multirreferencial (plural) das situações educativas e formativas. Em J. G. Barbosa, (Coord.). Multirreferencialidade nas ciências e na educação. São Carlos: UFScar, 2441.

Bracht, V. (2003). Educação Física \& Ciência: cenas de um casamento (in)feliz. 2. ed. Ijuí: Ed. Unijuí.

Brasil. (2007). CAPES. Portaria Normativa n. 38, de 12 de dezembro de 2007. Dispõe sobre o PIBID Programa Institucional de Bolsa de Iniciação à Docência, no âmbito da CAPES. Diário Oficial da União. Brasília, 39, dez. 2007. Seção 1.

Farias, I. M. S. de; Rocha, C. C. T. (2012). PIBID: uma política de formação docente inovadora? Revista Cocar, 6(11), 41-49.

Ferraroti, F. (2014). História e histórias de vida: o método biográfico nas ciências sociais. Tradução Galvão, C. E \& Passegi, M. Natal: Edufrn.

Galvani, P. (2002). A autoformação, uma perspectiva transpessoal, transdisciplinar e transcultural. Em: Educação e transdisciplinaridade, II. CETRANS, São Paulo: Triom. 
Garcia, C. M. (1999). Formação de Professores: Para uma Mudança Educativa. Porto (Portugal): Porto Editora.

Josso, M. C. (2007). A transformação de si a partir da narração de histórias de vida. Porto Alegre/RS, ano $X X X, 3$ (63), 413-438.

Josso, M. C. (2004). Experiências de Vida e Formação. São Paulo: Cortez.

Medeiros et al. (2017). PIBID e Formação para a Educação Física Escolar: Notas de uma etnografia. Pensar a Prática, 20(4). doi: 10.5216/rpp.v20i4.40409

Mizukami, M. G. N. (Ed.). (2010). Escola e aprendizagem da docência: processo de investigação e formação. São Carlos: EDuFSCAr.

Macedo. R. S. (2010). Compreender/ mediar a formação: o fundante da educação. Brasília: Liber Livro Editora.

Nóvoa, A. (1992). A formação de professores e profissão docente. In: Nóvoa, A. (org.). Os professores e sua formação. Lisboa: publicações Dom Quixote.

Passegi, M. da C. (2002). As duas faces do memorial acadêmico. Odisséia, 9, (13-14), 65-75.
Pineau, G. (1988). A autobiografia no decurso da vida: entre a hetero e a ecoformação. Em: Finger, M. e Nóvoa (Org). O método (auto) biográfico e a formação. Cadernos de Formação1. Lisboa: Ministério da Saúde, 65-77.

Pinto, C. S. (2014). A formação do professor críticoreflexivo na educação física: realidades e possibilidades no âmbito do PIBID IFCE. Dissertação de mestrado não publicada, Universidade Estadual do Ceará, Fortaleza, Brasil.

Ricouer, P. (1996). Teoria da interpretação. Trad. de Artur Morão. Lisboa(70).

Souza, E. C. (2006). A arte de contar e trocar experiências: reflexões teóricometodológicas sobre as histórias de vida em formação (Versão Online). Educação em Questão, 1 (25), 22-39.

Schön, D. (1992). Formar professores como profissionais reflexivos. Em: Nóvoa, A. (coord.) Os professores e a sua formação. Lisboa: Dom Quixote, 77-91.

Therrien, J. (2006). Os Saberes da Racionalidade Pedagógica na Sociedade Contemporânea. Revista Educativa, 9(1), 67-81.

Todo o conteúdo da revista Motricidade está licenciado sob a Creative Commons, exceto quando especificado em contrário e nos conteúdos retirados de outras fontes bibliográficas. 